\title{
BMJ Open Is establishing a specialist back pain assessment and management service in primary care a safe and effective model? Twelve-month results from the Back pain Assessment Clinic (BAC) prospective cohort pilot study
}

John H Y Moi, ${ }^{1}$ Uyen Phan, ${ }^{2}$ Adam de Gruchy, ${ }^{2}$ Danny Liew, ${ }^{3}$ Tanya I Yuen, ${ }^{4}$ John E Cunningham, ${ }^{5}$ lan $\mathrm{P}$ Wicks ${ }^{1,6}$

To cite: Moi JHY, Phan U, de Gruchy $\mathrm{A}$, et al. Is establishing a specialist back pain assessment and management service in primary care a safe and effective model? Twelve-month results from the Back pain Assessment Clinic (BAC) prospective cohort pilot study. BMJ Open 2018;8:e019275. doi:10.1136/ bmjopen-2017-019275

- Prepublication history for this paper is available online. To view these files, please visit the journal online (http://dx.doi. org/10.1136/bmjopen-2017019275).

Received 8 September 2017 Revised 4 July 2018 Accepted 22 August 2018
Check for updates

(C) Author(s) (or their employer(s)) 2018. Re-use permitted under CC BY-NC. No commercial re-use. See rights and permissions. Published by BMJ.

For numbered affiliations see end of article.

Correspondence to Dr John H Y Moi; john.moi@mh.org.au

\section{ABSTRACT}

Objectives To report on the design, implementation and evaluation of the safety and effectiveness of the Back pain Assessment Clinic (BAC) model.

Design BAC is a new, community-based specialist service for assessing and managing neck and low back pain (LBP). The BAC pilot was supported by a Victorian Department of Health and Human Services grant and was evaluated using the Victorian Innovation Reform Impact Assessment Framework (VIRIAF). Data were obtained by auditing BAC activity (22 July 2014 to 30 June 2015) and conducting surveys and interviews of patients, stakeholders and referrers.

Setting Tertiary and primary care.

Participants Adult patients with neck and LBP referred for outpatient surgical consultation.

Main outcome measures VIRIAF outcomes: (1) access to care; (2) appropriate and safe care; (3) workforce optimisation and integration; and (4) efficiency and sustainability.

Results A total of 522 patients were seen during the pilot. Most were referred to hospital services by general practitioners (87\%) for LBP $(63 \%)$ and neck pain $(24 \%)$. All patients were seen within 10 weeks of referral and commenced community-based allied health intervention within 2-4 weeks of assessment in BAC. Of patients seen, $34 \%$ had medications adjusted, $57 \%$ were referred for physiotherapy, $3.2 \%$ to pain services, $1.1 \%$ to rheumatology and $1.8 \%$ for surgical review. Less MRI scans were ordered in BAC (6.4\%) compared with traditional spinal surgical clinics (89.8\%), which translated to a cost-saving of $\$ 52560$ over 12 months. Patient and staff satisfaction was high. There have been no patient complaints or adverse incidents.

Conclusion Evaluation of the BAC pilot suggests it is a potentially safe and cost-saving alternative model of care. Results of the BAC pilot merit further evaluation to determine the potential cost-effectiveness, longer term and broader societal impact of implementing BAC more widely.
Strengths and limitations of this study

- One of the first studies to evaluate the outcomes of patients managed in a primary care-based specialist service for assessing and managing neck and low back pain referrals to public hospitals, including patient reported functional outcomes and patient, clinician and referrer satisfaction.

- Longer duration of patient cohort follow-up compared with other studies of alternative care models for neck and low back pain.

- More substantial cost-effective analysis than provided by other studies of alternative models of care for neck and low back pain.

- Our study findings are subject to the limitations of an observational study design.

- Interpretation of the evaluation is restricted by the modest sample size of patient and GP responses, limited economic analysis, absence of long-term follow-up and our study lacked a historical comparator group.

\section{INTRODUCTION}

Worldwide, low back pain (LBP) and neck pain are the most prevalent and disabling musculoskeletal conditions in the community ${ }^{12}$ and affects people of all ages in high-, middle- and low-income countries. ${ }^{3}$ LBP, in particular, places great demands on primary care $^{4}$ and hospital resources. ${ }^{5-7}$ It is the leading musculoskeletal complaint seen in both general practice ${ }^{4}$ and hospital emergency departments, ${ }^{7}$ and UK Hospital Episode Statistics reports that the rates of hospitalisation and inpatient procedures performed for LBP have significantly risen, by 2.3-fold and 2.8-fold, respectively, in recent years. ${ }^{8}$ Similarly, the 2009-2010 National Health 


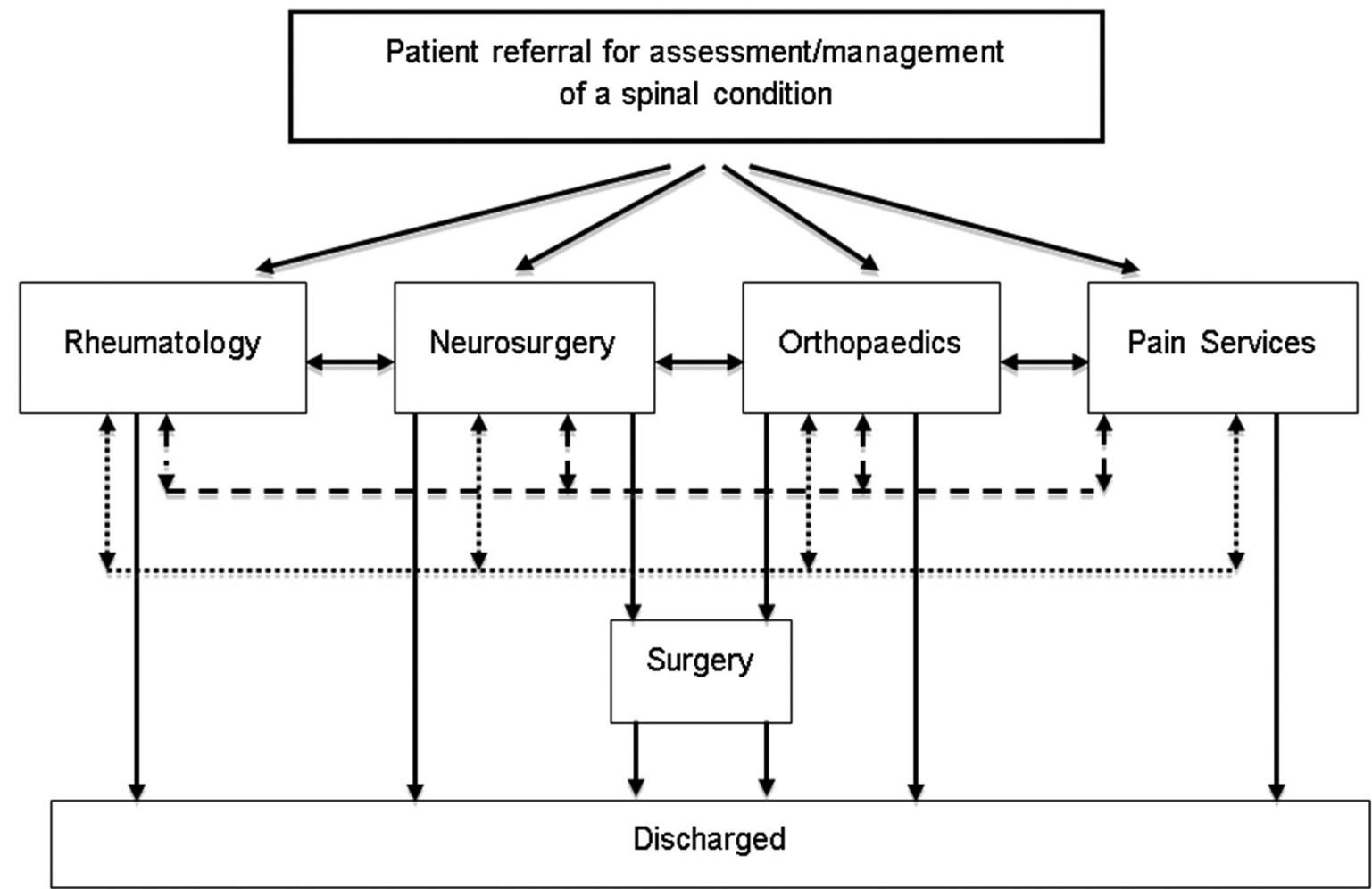

Figure 1 Traditional/existing service model in most Australian hospitals for managing outpatient referrals for specialist care of low back and neck pain.

and Nutrition Examination Survey found that compared with individuals without LBP, adults with chronic LBP in the USA were 3.3 times more likely to report $\geq 10$ visits to healthcare providers and overnight hospitalisation per annum. ${ }^{9}$

Although most guidelines recommend that LBP should be managed in primary care, many patients are still referred for outpatient surgical review. ${ }^{10}{ }^{11}$ High referral rates are associated with lengthy waits for initial consultation and delays in care for appropriate candidates for surgery. ${ }^{10}$ For example, our institution, The Royal Melbourne Hospital (RMH), is a large Australian metropolitan public hospital with over 500 inpatient beds and serves as a tertiary neurosurgery and orthopaedic referral centre. An audit of the neurosurgery outpatient waiting list in 2013 revealed that $68.5 \%$ of all 'non-urgent' referrals (971 of 1418) were made for neck or LBP, and the mean wait time for an initial consultation was 18 months. Other factors identified as contributing to delays in care within the existing system (shown in figure 1) include the lack of appropriate conservative management prior to referral for specialist consultation, referral of patients to multiple specialist services for the same problem, which further compound lengthy waits to accessing specialists, the lack of streamlined care pathways between different specialist services within hospitals and between tertiary and primary care and the fact that the vast majority $(\geq 90 \%)$ of patients referred to surgical clinics do not require surgery ${ }^{12}$ but are discharged without referral for conservative management.
Alternative models of care are therefore needed that provide patients with more timely access to expert assessment and evidence-based management. The aim of this study was to report on the design, implementation and initial evaluation of a novel care model called the 'Back pain Assessment Clinic' (BAC), which was established as an alternative pathway for providing community-based, outpatient specialist review of neck and LBP.

\section{METHODS}

BAC model and pilot

The BAC model and care pathways were developed as a collaborative initiative between rheumatology, neurosurgery, orthopaedics, chronic pain and physiotherapy services at RMH to provide patients within RMH's primary catchment area with rapid access to community-based specialist care for neck and LBP. Weekly clinics were established at a community health centre (Merri Health $(\mathrm{MH})$ ) and RMH's Royal Park (subacute) campus. BAC was staffed by advanced practice physiotherapists (APPs) and a rheumatology registrar who worked under the guidance of a rheumatologist. The APPs were senior physiotherapists who had postgraduate qualifications, credentialing in advanced practice ${ }^{13}$ and extensive experience in spinal surgery clinics.

A 'centralised triage process' was developed to support BAC's implementation. This involved a rheumatologist (JHYM), neurosurgeon (TIY), orthopaedic spinal surgeon (JEC) and APP (UP) meeting fortnightly to triage new 
Box 1 Consensus inclusion and exclusion criteria for Back pain Assessment Clinic (BAC)

\section{Inclusion criteria}

- New and existing referrals for neck or low back pain (LBP) already on outpatient spinal surgical waiting lists.

- Referrals for patients that live within the hospital's primary catchment area.*

- Referrals triaged 'non-urgent' or assigned a 'next available' appointment by neurosurgery and orthopaedic spinal units.

- Spinal pain with or without referred limb symptoms.

- Absence of 'red flags'.

- Low likelihood of surgical intervention.

- Age greater than 16 years.

\section{Exclusion criteria}

- Radiological or clinical features confirming or raising the suspicion of 'red flags', for example, spinal infection, malignancy, fracture, spinal inflammation, spinal cord compression (eg, cervical myelopathy) or cauda equina syndrome.

- Spinal trauma, instability (eg, atlantoaxial instability), recent spinal fracture or spinal surgery within the last 2 years.

- Brain or spinal cord injury or malformation.

- Radiological evidence of moderate-to-severe central canal stenosis, lateral recess or foraminal stenosis or a large disc protrusion accompanied by signs and symptoms of radiculopathy or neurogenic claudication.

- Worsening upper or lower motor neuron deficits.

- Radiculopathy accompanied by limb weakness, for example, foot drop.

- Moderate-to-severe scoliosis with Cobb angle $>20^{\circ}$.

- Peripheral entrapment neuropathies, for example, carpal tunnel syndrome.

- High likelihood of need for surgical intervention.

- Failed adequate trial of non-operative management for a potentially surgically amenable condition (eg, spondylolisthesis with persistent symptoms).

- Presence of a comorbid condition that also requires surgical assessment and management.

- Referral from another hospital surgeon or physician to neurosurgery or orthopaedic spinal surgery.

- Patients already well known to neurosurgery, orthopaedics, rheumatology or chronic pain services.

- Referrals for consideration of spinal surgical device implantation (eg, spinal cord stimulators).

- Patient and/or general practitioner preference for patients to be assessed by a surgeon.

- Patients referred for medicolegal opinions or compensable claims for example, Transport Accident Commission, WorkSafe Victoria.

*Catchment area refers to the geographical area surrounding the hospital, from which patients are eligible to use its services.

referrals for spinal pain either to BAC or the appropriate outpatient specialist clinic. Consensus criteria were established regarding the conditions that were suitable for BAC (box 1). In general, referrals were excluded from BAC if surgery was considered highly likely or 'red flag' causes of neck and LBP were present; the latter were escalated for rapid specialist consultation.

Patients and referrers were sent written information about the BAC pilot prior to being offered an appointment. All patients provided verbal consent to participating in the pilot. Patients were assessed in BAC within 10 weeks of referral. Prior to BAC consultation, patients received a questionnaire that collected information on demographics, medical history, Brief Pain Inventory (BPI) short form ${ }^{14}$ and Oswestry Disability Index (ODI) ${ }^{15}$ or Neck Disability Index (NDI) scores. ${ }^{16}$ In BAC, patients were clinically assessed and screened for 'red flags', questionnaire responses were reviewed and an evidence-based management plan was developed, which included a review of patient analgesia. Patients requiring active exercise intervention were referred and seen within 2-4 weeks in newly developed community-based spinal rehabilitation programmes ( $\mathrm{MH}$, Cohealth). Patients requiring neurosurgery, orthopaedic spinal surgery, rheumatology or chronic pain services were seen within 12 weeks with appropriate investigations arranged (figure 2). After completing the 12-week community-based spinal rehabilitation programme, patients were reassessed using the ODI/NDI, BPI (BPI-I: interference, BPI-S: severity) and Global Improvement Scale (GIS). ${ }^{17}$

The BAC pilot ran from 22 July 2014 to 30 June 2015, funded by a Workforce Innovation Grant from the Victorian Department of Health and Human Services (DHHS). Appropriate patients within RMH's primary catchment area already on the outpatient surgical waiting lists were also offered a BAC appointment. The assessment (BAC) and management clinics (MH) became known collectively as the 'Back pain Assessment and Management Service'.

\section{Evaluation framework, study outcomes and data collection}

BAC was evaluated using the Victorian Innovation Reform Impact Assessment Framework (VIRIAF), ${ }^{18}$ in line with Victorian DHHS requirements. Key areas of evaluation were: (1) access to care; (2) appropriate and safe care; (3) workforce optimisation and integration; and (4) efficiency and sustainability. The four domains of the VIRIAF served as the primary study outcomes for the BAC pilot.

Quantitative data were obtained from auditing the centralised triage process and BAC activity from 22 July 2014 to 30 June 2015. Qualitative data were collected from surveys and interviews of patients $(n=54)$, stakeholders (includes neurosurgeons, orthopaedic surgeons, rheumatologists, hospital and community health managers and physiotherapists) $(\mathrm{n}=14)$ and referrers $(\mathrm{n}=26)$ between 1 March 2015 and 30 June 2015 (table 1).

\section{Statistical methods}

Descriptive data were summarised using mean (SD) or median (IQR) for continuous variables and $\mathrm{n}(\%)$ for categorical variables. Data on referral sources and waiting times were analysed for the whole cohort, while health services utilisation was analysed according to two subgroups: (1) patients referred to and reviewed in BAC and (2) patients referred to but not reviewed in BAC. MRI costs were calculated using the Medicare Benefits Schedule fee of $\$ 358.40$ for spinal MRI (item numbers 63161, 63164, 63167, 63170, 63173, 63176, 63179, 


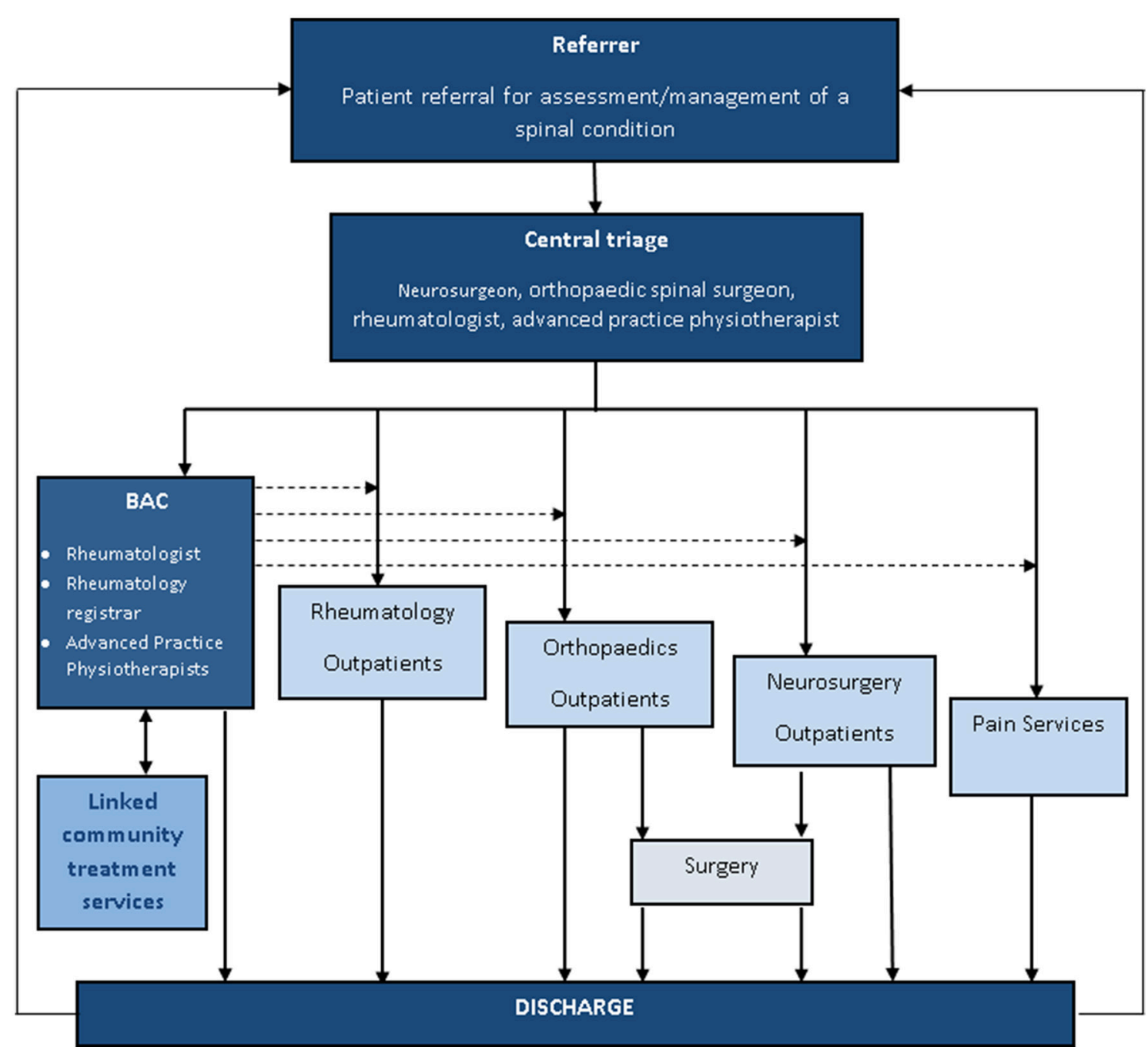

Figure 2 Health service redesign for managing low back and neck pain referrals implemented during the Back pain Assessment Clinic (BAC) pilot.

63182 and 63185), and the MRI utilisation rates in outpatient neurosurgery clinics for assessing spinal conditions was assumed to be $89.8 \%$ in line with published data. ${ }^{19}$ All analyses were performed using SPSS, V.22.0.

\section{Patient and public involvement}

A steering committee was formed to oversee the BAC pilot and included consumer representation. The consumer representative provided input on the research question, development of patient and referrer study information sheets, patient questionnaires used for data collection and study evaluation. Results from the BAC pilot were made available to study participants who requested a copy of the research findings.

\section{RESULTS}

\section{Study population}

Patient demographics are summarised in table 2. The majority $(73.7 \%)$ of new referrals to RMH surgical clinics were deemed appropriate for BAC by the centralised triage team. In total, 522 in-catchment patients were referred to BAC $(83.3 \%$ redirected from neurosurgery and $13.2 \%$ from orthopaedics), of whom $51.5 \% \quad(n=272)$ were new referrals and $48.5 \%(n=250)$ were drawn from specialist clinic waiting lists. Most referrals were made by general practitioners (GPs) $(87 \%)$ for LBP $(63 \%)$ or neck pain (24\%).

At the end of the pilot, $292(55.9 \%)$ eligible patients had been reviewed in BAC (designated the BAC 'seen' group). Of the remaining 230 patients (designated the BAC 'not seen' group), 91 (17.4\%) accepted but had not yet attended, 68 (13\%) declined all services (the majority because their spinal symptoms had resolved), 61 (11.7\%) were uncontactable, $2(0.4 \%)$ had died and $5(1 \%)$ had already attended an outpatient surgical appointment. Only three patients $(0.6 \%)$ declined a BAC appointment. Of the 292 patients reviewed, complete data were available for $285(97.6 \%)$ patients. Seven were excluded from the analysis due to incorrect or incomplete information. The mean $(\mathrm{SD})$ age of patients seen $(\mathrm{n}=285)$ and referred but not seen in BAC $(\mathrm{n}=230)$ were 53.9 (16.8) and 53.6 (17) years, respectively. The gender distribution 
Table 1 Study outcomes as defined by the four domains of the Victorian Innovation Reform Impact Assessment Framework (VIRIAF) and the data sources and collection methods used

\begin{tabular}{|c|c|c|}
\hline VIRIAF domains & Outcomes & $\begin{array}{l}\text { Data sources and collection } \\
\text { methods* }\end{array}$ \\
\hline Access to care & $\begin{array}{l}\text { Patients receive timely access to expert management of } \\
\text { low back and neck pain. } \\
\text { Patients receive convenient access to services within } \\
\text { their local community. } \\
\text { Patients receive timely access to specialist surgical, } \\
\text { rheumatology, chronic pain management and allied } \\
\text { health services where indicated through newly } \\
\text { developed and streamlined referral pathways of care. }\end{array}$ & $\begin{array}{l}\text { Clinic audit. } \\
\text { Patient survey and interview. } \\
\text { Referrer survey and interview. } \\
\text { Stakeholder interview. }\end{array}$ \\
\hline Appropriate and safe care & $\begin{array}{l}\text { Patients with back or neck pain are directed to the most } \\
\text { appropriate clinical service, including appropriate non- } \\
\text { surgical management for those who either do not require } \\
\text { or are unlikely to benefit from spinal surgery. } \\
\text { Patients redirected from neurosurgery, orthopaedic } \\
\text { spinal, rheumatology and pain services experience no } \\
\text { adverse outcomes. } \\
\text { Patients receive appropriate clinical services based on } \\
\text { need and clinical evidence. } \\
\text { Patients experience continuity of care. }\end{array}$ & $\begin{array}{l}\text { Clinic and triage audit. } \\
\text { Audit of hospital administrative } \\
\text { data. } \\
\text { Patient survey and interview. } \\
\text { Referrer survey and interview. } \\
\text { Stakeholder interview. } \\
\text { Clinician survey and interview. }\end{array}$ \\
\hline $\begin{array}{l}\text { Workforce optimisation } \\
\text { and integration }\end{array}$ & $\begin{array}{l}\text { Service development and delivery involves } \\
\text { multidisciplinary and cross-organisational collaboration, } \\
\text { which also contributes to ongoing knowledge and skill } \\
\text { development. } \\
\text { Surgeon time and skills are optimised towards assessing } \\
\text { and managing patients with back or neck problems that } \\
\text { are more likely to benefit from surgery and for conditions } \\
\text { that are more time critical. } \\
\text { Advanced practice physiotherapist's and } \\
\text { rheumatologist's skills are optimally used to assess and } \\
\text { manage patients with back and neck pain. } \\
\text { The community health workforce capacity is expanded } \\
\text { to include management of more complex patients with } \\
\text { back and neck pain. }\end{array}$ & $\begin{array}{l}\text { Clinician survey and interview. } \\
\text { Referrer survey and interview. } \\
\text { Stakeholder interview. } \\
\text { Patient survey and interview. }\end{array}$ \\
\hline
\end{tabular}

${ }^{*}$ Apart from the collection of patient surveys, which was conducted during the BAC pilot, all other data collection was performed at the conclusion of the 12-month pilot project.

in both groups was similar $(47.7 \%$ and $43.9 \%$ males, respectively).

\section{Access to care}

For 194 newly referred patients reviewed in BAC, the mean (SD) time from referral to initial consultation was 9.8 (4.3) weeks, including referrals received 3 months prior to BAC's commencement. Of the 119 patients redirected from neurosurgery and orthopaedic outpatient waiting lists, the respective mean (SD) waiting times were 101.3 (42.4) and 70.5 (40.1) weeks (equating to a weighted average of 100 weeks).

Of GPs who were aware of BAC $(n=18), 61 \%$ felt BAC had improved access to care, and only two respondents indicated a preference for a surgeon to see their patients. Eight GPs (30.8\%) indicated they were unaware of BAC, most likely because BAC was not advertised to GPs during the pilot. Surveyed patients $(n=54)$ rated attending BAC at the community health centre as easier than travelling to RMH's acute hospital campus.

\section{Appropriate and safe care}

A percentage of 92.8 of patients in BAC were seen by the same clinician throughout their contact with the service, maintaining continuity of care. Following BAC consultation, $34 \%$ of patients had medications adjusted, $6 \%$ underwent a spinal injection (eg, nerve root block), $57 \%$ were referred for community-based spinal rehabilitation 
Table 2 Baseline characteristics of patients in the BAC 'seen' and 'not seen' groups

\begin{tabular}{|c|c|c|c|}
\hline Variable & $\begin{array}{l}\text { 'BAC seen' } \\
\mathrm{n}=285\end{array}$ & $\begin{array}{l}\text { 'BAC, not seen' } \\
\mathrm{n}=230\end{array}$ & $\begin{array}{l}\text { Total } \\
n=515\end{array}$ \\
\hline Male: $n(\%)$ & $136(47.7)$ & $101(43.9)$ & $237(46.0)$ \\
\hline Age in years at time of referral: mean (SD) & $53.9(16.8)$ & $53.6(17.0)$ & $53.8(16.9)$ \\
\hline \multicolumn{4}{|l|}{ Catchment: $\mathrm{n}(\%)$} \\
\hline Merri CHS & $161(56.5)$ & $151(65.7)$ & $312(60.6)$ \\
\hline Cohealth & $124(43.5)$ & 79 (34.3) & $203(39.4)$ \\
\hline \multicolumn{4}{|l|}{ Referral source: n (\%) } \\
\hline General practitioner & $250(87.7)$ & $204(88.7)$ & $454(88.2)$ \\
\hline Melbourne Health & 35 (12.3) & $25(10.9)$ & $60(11.7)$ \\
\hline Other public hospital & $0(0)$ & $1(0.4)$ & $1(0.2)$ \\
\hline \multicolumn{4}{|l|}{ Clinic referred to: $\mathrm{n}(\%)$} \\
\hline Neurosurgery & $230(80.7)$ & $199(86.5)$ & 429 (83.3) \\
\hline Orthopaedics & $43(15.1)$ & $25(10.9)$ & $68(13.2)$ \\
\hline Rheumatology & $4(1.4)$ & $4(1.7)$ & $8(1.6)$ \\
\hline Pain service & $5(1.8)$ & $1(0.4)$ & $6(1.2)$ \\
\hline BAC & $3(1.1)$ & $1(0.4)$ & $4(0.8)$ \\
\hline Already on clinic waiting list, $n$ (\%) & $121(42.5)$ & $129(56.1)$ & $250(48.5)$ \\
\hline
\end{tabular}

BAC, Back pain Assessment Clinic; Merri CHS, Merri Community Health Service.

and $6.1 \%$ were referred to another specialist service: five $(1.8 \%)$ to neurosurgery or orthopaedics, three $(1.1 \%)$ to rheumatology, nine $(3.2 \%)$ to chronic pain services. Fiftythree patients $(18.6 \%)$ were discharged after their initial BAC consultation. There were no patient complaints nor adverse incidents.

Analysis of available patient-reported outcomes (ODI/ NDI, BPI-I/BPI-S and GIS) showed improvements in all domains of disability, pain and overall well-being (table 3). In terms of patient-reported satisfaction, $94.4 \%$ of respondents recorded very high levels of satisfaction with the service, engagement with clinicians and clinicians' explanations. Similarly, $94.4 \%$ of respondents indicated they were 'very satisfied' $(62.9 \%)$ or 'satisfied' $(31.5 \%)$ with the service, 'very satisfied' (68.5\%) or 'satisfied' (29.6\%) with clinician care and either 'strongly agreed' (66.7\%) or 'agreed' (27.8\%) that their expectations had been met. Surveyed GPs $(n=26)$ expressed satisfaction with the communication received from BAC ('strongly agreed' $15.4 \%$, 'agreed' $42.3 \%$ ).

\section{Workforce optimisation and integration}

Surveys of stakeholders suggested that BAC promoted more efficient use of surgeons' skills and time. Stakeholders and GPs $(61.5 \%)$ regarded involving a rheumatologist in BAC was important for ensuring medical issues were identified and appropriately managed. Stakeholder feedback regarding the role of APP was also positive, although less than $40 \%$ of GPs felt they understood their role.

\section{Efficiency and sustainability}

The clinician costs of staffing BAC and traditional neurosurgery/orthopaedic clinics are summarised in table 4 . To review 15 patients in a 3.5-hour session, BAC costs $\$ 68.60$ per patient, compared with $\$ 44.80$ per patient seen in a surgical clinic, meaning a cost differential of $\$ 23.80$ per

\begin{tabular}{|c|c|c|c|}
\hline Outcome measure & $\mathbf{n}$ & Mean (SD) & $95 \% \mathrm{Cl}^{*}$ \\
\hline $\begin{array}{l}\text { Oswestry or Neck disability index (\%): change from first visit to latest } \\
\text { visit† }\end{array}$ & 33 & $-7.8(11.5)$ & -11.7 to -3.8 \\
\hline Brief Pain Inventory - Severity: change from first visit to last visit† & 18 & $-2.1(2.3)$ & -1.0 to -3.1 \\
\hline Brief Pain Inventory - Interference: change from first visit to last visit† & 20 & $-1.8(2.5)$ & -0.7 to -2.9 \\
\hline Global Improvement Scaleł: maximum category at any subsequent visit & 53 & $5.0(1.3)$ & 4.6 to 5.3 \\
\hline
\end{tabular}

${ }^{*}$ Mean $\pm 1.96 \times[\mathrm{SD} / \sqrt{ } \mathrm{n}]$.

†Negative value indicates improvement.

†Patient global impression of change from baseline (scale 1-7), whereby 1 equates to 'very much worse' and 7 to 'very much improved'.

BAC, Back pain Assessment Clinic. 
Table 4 Comparison of clinician costs of staffing BAC and traditional surgical clinics

\begin{tabular}{|c|c|c|}
\hline & BAC & $\begin{array}{l}\text { Neurosurgical/orthopaedic } \\
\text { clinic }\end{array}$ \\
\hline Consultants & $\begin{array}{l}1 @ \$ 135 / \text { hour } \\
\text { (HN29, midtier) }\end{array}$ & $\begin{array}{l}1 @ \$ 135 / \text { hour } \\
\text { (HN29, midtier) }\end{array}$ \\
\hline Registrars & $\begin{array}{l}1 @ \$ 57 / \text { hour } \\
\text { (HM29, upper tier) }\end{array}$ & $\begin{array}{l}1 @ \$ 57 / \text { hour } \\
\text { (HM29, upper tier) }\end{array}$ \\
\hline Advanced practice physiotherapist $\times 2$ & $\begin{array}{l}\$ 51 / \text { hour } \\
\text { (VC8, upper tier) }\end{array}$ & N/A \\
\hline Number of patients seen per session (3.5 hours) & 15 & 15 \\
\hline Cost per patient seen & $\$ 68.60$ & $\$ 44.80$ \\
\hline Total staff costs for 3.5 hour session & $\$ 1029$ & $\$ 672$ \\
\hline
\end{tabular}

patient. However, BAC was associated with substantial cost savings through reduced MRI usage. Among the 285 patients seen in BAC, 97 (34\%) had already undergone MRI scanning prior to BAC attendance, while a further 18 patients $(6.3 \%)$ were referred for an MRI after BAC assessment. Compared with standard practice in existing surgical clinics, BAC reduced the proportion of patients having MRI scans from an assumed $89.8 \%{ }^{19}$ to $40.3 \%$ (absolute difference $49.5 \%$ ), conferring a cost-saving of $\$ 180$ per patient or total cost-saving of $\$ 52560$ during the pilot.

\section{DISCUSSION}

Evaluation of the BAC pilot demonstrates it is a potentially safe and effective model for managing referrals to hospital services for neck and LBP. BAC is a collaborative initiative that integrates tertiary hospital stakeholders and community health services to deliver more coordinated and efficient care. This was made possible through: (1) establishing the BAC clinical pathway that provides patients with streamlined access to community- and hospital-based expertise, (2) DHHS funding and (3) unprecedented cooperation and good will from stakeholders. BAC helped transform typically fragmented and variable care of LBP in current service models and was associated with high levels of patient reported satisfaction.

Establishing BAC as a community- and catchment-based service provided convenient access to tertiary care expertise and improved communication and coordination of care between tertiary and primary care clinicians. This was favourably regarded by stakeholders. The process to establish stakeholder consensus criteria for referral to BAC encouraged confidence that patients were triaged to the most appropriate service and care was not compromised. This was supported by the finding that most referrals $(73.7 \%)$ were deemed appropriate for BAC and following assessment in BAC, only $1.8 \%$ required surgical review. Moreover, there were no adverse patient outcomes. The centralised triage process also provided a single entry point for all referrals for neck and LBP. This allowed the service to: (1) 'sort' referrals and triage them to the most appropriate service, (2) consolidate duplicate referrals made to multiple specialties for a single patient,
(3) calibrate clinicians from different disciplines in triaging referrals, (4) apply and refine the BAC consensus criteria and (5) regularly hold multidisciplinary case conferencing and share expertise.

BAC was associated with substantially lower MRI utilisation compared with surgical clinics. This translated to a saving of $\$ 52560$ during the pilot and a substantial opportunity cost of improved MRI access for other patients. Beyond savings in MRI costs, BAC improved patient access to evidence-based care (eg, patients received care 90 weeks or 1.7 years earlier) and promoted more effective deployment of surgeons' skill and time. Finally, rheumatology involvement provided the APPs and registrar with specialist support for patient assessment (eg, requesting and interpreting investigations) and optimising non-surgical management (eg, analgesia review, performing diagnostic/therapeutic joint injections and referral for spinal nerve blocks). This was favourably regarded by referrers and stakeholders.

There are few studies of models of care for neck and LBP, and none have been comprehensively evaluated. ${ }^{1112} 2021$ Preliminary evidence from APP-led triage services from Australia, ${ }^{21}$ the $\mathrm{USA}^{20}$ and Canada ${ }^{11}{ }^{12}$ demonstrate similar trends in improved patient satisfaction, referral practices, reduced waiting times, cost and potentially improved patient outcomes. The BAC model differed in several respects. First, BAC is likely to have less risk of missing 'red flags' given these referrals are excluded from BAC (box 1) and are carefully screened for using a standardised pro forma during BAC consultation. Second, the centralised triage process is unique to BAC and facilitated standardisation of clinician triage practices. After completion of the pilot, centralised triage was performed by the BAC rheumatologist and APPs. Third, the BAC clinical pathways provided patients with streamlined access to communityand hospital-based services. Fourth, BAC provided more holistic and efficient patient care through involvement of a rheumatologist to ensure that evidence-based management was adequately trialled, and appropriate investigations were organised prior to surgical review. Finally, BAC is one of the first tertiary neck and LBP services to have been established in primary care. 
Our study findings are subject to the limitations of an observational study design. Interpretation of the evaluation is restricted by the modest sample size of patient and GP responses, limited economic analysis (including omission of the central triage process staffing costs), absence of long-term follow-up and our study lacked a historical comparator group. We were also unable to track the progress of patients who had been directly triaged to attend traditional specialist services rather than BAC which, if known, may have provided a more complete picture of the effect of the BAC model, particularly the central triage process. The BAC model therefore warrants further validation using a rigorous comparative analysis to routine care, ideally in the form a randomised clinical trial. At the time of manuscript submission, the Victorian DHHS has funded replication of the BAC model in three other Victorian hospitals. Evaluation of BAC's implementation at other sites will help further validate findings from the pilot study.

\section{CONCLUSION}

The BAC model is a novel care pathway that provides patients with neck and LBP with streamlined access to community-based expert assessment and spinal rehabilitation, as well as hospital-based specialist expertise. The results of this pilot study suggest that BAC is a potentially safe and cost-saving alternative model of care, associated with substantial reductions in MRI usage compared with traditional surgical clinics. The initial findings from the BAC pilot merit further evaluation to determine the cost-effectiveness, longer term and broader societal impact of implementing BAC more widely.

\section{Author affiliations}

${ }^{1}$ Department of Rheumatology, The Royal Melbourne Hospital, Melbourne, Victoria, Australia

${ }^{2}$ Department of Physiotherapy, The Royal Melbourne Hospital, Parkville, Victoria, Australia

${ }^{3}$ School of Public Health and Preventive Medicine, Monash University, Melbourne, Victoria, Australia

${ }^{4}$ Department of Neurosurgery, The Royal Melbourne Hospital, Parkville, Victoria, Australia

${ }^{5}$ Department of Orthopaedics, The Royal Melbourne Hospital, Parkville, Victoria, Australia

${ }^{6}$ Department of Inflammation, Walter and Eliza Hall Institute of Medical Research, Melbourne, Victoria, Australia

Acknowledgements The study authors would like to acknowledge the contribution of the Victorian Department of Health and Human Services (Kathleen Philip and Josie Vocale), BAC steering committee members (Professor Peter Teddy, Assistant Professor Genevieve Juj, Samantha Plumb, Kelly Skene, Sandra Savy, Fiona McCormack, Diane Steward, Assistant Professor Malcolm Hogg, Dr Sue Hookey and Dr Debra Wilson), MH executive (Dr Gareth Goodier and Assistant Professor Kate Drummond), MH Heads of Units (Professor Andrew Kaye and Assistant Professor Andrew Bucknill) and community partners at Merri Health (Nigel Fidgeon, Dr Antoinette Mertins, Christine Ferlazzo, Lucien Deane-Johns, Catherine Austin, Yashwant Rath and Reshma Matthias) and coHealth (Greg Bourke, Manasi Salvi and Chris Platt) for their partnership in establishing the BAC/BAMS service.

Contributors Study design: all authors; data acquisition: JHYM, UP and AdG; data analysis and interpretation: all authors; statistical analysis: DL. JHYM takes responsibility that this study has been reported honestly, accurately and transparently and is the study guarantor. All authors contributed important intellectual content during manuscript drafting and revision, accept accountability for the work and have approved the final version for publication.

Funding The study was funded by a Workforce Innovation Grant provided by the Victorian State Government Department of Health and Human Services. IPW is supported by a Clinical Practitioner Fellowship from the National Health and Medical Research Council (NHMRC; 1023407) and an NHMRC Program Grant (1016647).

Competing interests None declared.

Patient consent Obtained.

Ethics approval The BAC pilot evaluation was approved by the Melbourne Health Human Research Ethics Committee (QA2014148).

Provenance and peer review Not commissioned; externally peer reviewed.

Data sharing statement The authors agree to share deidentified participant data reported in the study. Proposals should be directed to the corresponding author. To gain access, data requestors will need to sign a data access agreement. Data will be available for up to 24 months following article publication.

Open access This is an open access article distributed in accordance with the Creative Commons Attribution Non Commercial (CC BY-NC 4.0) license, which permits others to distribute, remix, adapt, build upon this work non-commercially, and license their derivative works on different terms, provided the original work is properly cited, appropriate credit is given, any changes made indicated, and the use is non-commercial. See: http://creativecommons.org/licenses/by-nc/4.0/.

\section{REFERENCES}

1. Hoy D, March L, Brooks P, et al. The global burden of low back pain: estimates from the global burden of disease 2010 study. Ann Rheum Dis 2014;73:968-74.

2. GBD 2015 Disease and Injury Incidence and Prevalence Collaborators. Global, regional, and national incidence, prevalence, and years lived with disability for 310 diseases and injuries, 19902015: a systematic analysis for the Global Burden of Disease Study 2015. Lancet 2016;388:1545-602.

3. Hartvigsen J, Hancock MJ, Kongsted A, et al. What low back pain is and why we need to pay attention. Lancet 2018;391:2356-67.

4. Britt HM, Henderson GC, Bayram J, et al. General practice activity in Australia 2014-15. Sydney: Sydney University Press.

5. Drazin D, Nuño M, Patil CG, et al. Emergency room resource utilization by patients with low-back pain. J Neurosurg Spine 2016;24:686-93.

6. Lovegrove MT, Jelinek GA, Gibson NP, et al. Analysis of 22,655 presentations with back pain to Perth emergency departments over five years. Int J Emerg Med 2011;4:59.

7. Edwards J, Hayden J, Asbridge M, et al. Prevalence of low back pain in emergency settings: a systematic review and meta-analysis. BMC Musculoskelet Disord 2017;18:143.

8. Sivasubramaniam V, Patel HC, Ozdemir BA, et al. Trends in hospital admissions and surgical procedures for degenerative lumbar spine disease in England: a 15-year time-series study. BMJ Open 2015;5:e009011.

9. Shmagel A, Foley R, Ibrahim H. Epidemiology of chronic low back pain in US Adults: data from the 2009-2010 National Health and Nutrition Examination Survey. Arthritis Care Res 2016;68:1688-94.

10. ASERNIP-S. Spinal surgery for chronic low back pain: review of clinical evidence and guidelines. Australia: Australian Safety and Efficacy Register of New Interventional Procedures - Surgical (ASERNIP-S): rapid review. 2014.

11. Bath B, Grona SL, Janzen B. A spinal triage programme delivered by physiotherapists in collaboration with orthopaedic surgeons. Physiother Can 2012;64:356-66.

12. Kindrachuk DR, Fourney DR. Spine surgery referrals redirected through a multidisciplinary care pathway: effects of nonsurgeon triage including MRI utilization. J Neurosurg Spine 2014;20:87-92.

13. Department of Health. Victorian Government, 2016. Overview of allied health credentialing competency and capability framework. https://www2.health.vic.gov.au/health-workforce/allied-healthworkforce/allied-health-ccc-framework (accessed 16 Sep 2016).

14. Keller S, Bann CM, Dodd SL, et al. Validity of the brief pain inventory for use in documenting the outcomes of patients with noncancer pain. Clin J Pain 2004;20:309-18.

15. Fairbank JC, Couper J, Davies JB, et al. The Oswestry low back pain disability questionnaire. Physiotherapy 1980;66:271-3.

16. Vernon $\mathrm{H}$. The neck disability index: state-of-the-art, 1991-2008. J Manipulative Physiol Ther 2008;31:491-502. 
17. Kamper SJ, Maher CG, Mackay G. Global rating of change scales: a review of strengths and weaknesses and considerations for design. $J$ Man Manip Ther 2009;17:163-70.

18. Department of Health. Victorian Government, 2012. Victorian innovation and reform impact assessment framework. http:// docs.health.vic.gov.au/docs/doc/7B0C5DA18EC40820CA257A3A 00108038/\$FILE/Victorian\%20Innovation\%20and\%20Reform\% 201 mact\%20Assessment\%20Framework.pdf (accessed 27 Feb 2014)
19. Huang JG, Huang GH, Teddy PJ. Low back pain in neurosurgical outpatients: an audit. J Clin Neurosci 2008;15:1216-21.

20. Paskowski I, Schneider M, Stevans J, et al. A hospital-based standardized spine care pathway: report of a multidisciplinary evidence-based process. J Manipulative Physiol Ther 2011;34:98-106.

21. Blackburn MS, Cowan SM, Cary B, et al. Physiotherapy-led triage clinic for low back pain. Aust Health Rev 2009;33:663-70. 